\title{
Mega columns with several reinforced steel profiles - experimental and numerical investigations
}

\author{
T. Bogdan ${ }^{a^{*}}$ and M. Chrzanowski ${ }^{\text {b }}$ \\ aArcelorMittal Global R\&D, Construction and Infrastructure Application Department, Luxembourg \\ ${ }^{b}$ FSTC, RUES, AMCSFE, University of Luxembourg, Luxembourg \\ *corresponding author, e-mail address: teodora.bogdan@arcelormittal.com
}

\begin{abstract}
Steel reinforced concrete (SRC) columns are widely used in super high-rise buildings, since they can provide larger load bearing capacity and better ductility than traditional reinforced concrete (RC) columns.

Six concrete - encased composite columns were designed based on a typical megacolumn of a super high-rise building constructed in China. The specimens are identical in geometrical configurations having as changing parameter the eccentricity ratio of the applied load: every two of the specimens were loaded statically with the eccentricity ratio of $0,10 \%$, and $15 \%$, respectively.

Such columns are however not covered by EN 1994-1-1 [2] (limited to one single encased profile), while AISC 360-16 [8] allows the design of composite sections built-up with two or more encased steel sections, although the way to perform such a design is not detailed.

A finite element analysis was conducted as a supplement to the physical tests to provide a deeper insight into the behavior of SRC columns. The experimental campaign has yielded stable test results, suggesting a desirable performance of SRC columns. It is concluded from these experiments that sufficient composite action exists between the concrete and the steel sections for the tested SRC specimens, and that the current code provisions are applicable for the considered configuration, in predicting the flexural capacity of SRC columns when the eccentricity ratio is less than or equal to $15 \%$.

The present paper summarizes the principles and an application method for the design of such columns under combined axial compression and bending. The method is based on simplifications provided in EN 1994-1. The validation of the method is made using experimental and numerical results.
\end{abstract}

Keywords: Megacolumns; static tests; concrete columns reinforced by steel profiles; PDM method.

\section{Introduction}

Composite columns are frequently used in high rise buildings. Two commonly used types of composite columns for tall buildings are concrete encased composite columns and concrete filled steel tube columns. The concrete-encased composite column contains a structural steel with or without shear connectors and the surrounding concrete which is further reinforced by longitudinal bars and transverse bars. By utilizing the composite action between the concrete and the steel section, the capacity of the composite column is higher than the summation of the capacities of the concrete and the steel section [1].

A substantial number of experimental tests have been conducted to observe the behavior of concrete encased composite columns subjected to axial and eccentric loads.

The current design codes consider composite structural elements but they do not offer specific provisions on the design of composite sections with two or more encased steel sections. 
The lack of knowledge on the axial, bending and shear behavior of composite mega columns, along with the resulting lack of clarity in the codes, leads to the need for experimental performance tests. These tests provide a base for the simplified design approach and are used to calibrate numerical models to describe the designs and to validate the results. The experimental campaign took place within CABR Laboratories and the Laboratories of Tsinghua University, Beijing [4].

Experimental results are validated by finite element models (FEM) in accordance with the experimental values. FEM allow also for a deeper insight on steel-concrete interaction forces and stress distribution.

Finally, simplified design methods based on European, Chinese, and US codes are suggested and the results are compared to the numerical and experimental values. Then, through three examples of application to selected mega column cross- sections, the given simplified design methods are proven to be an effective and handy design tool.

\section{Experimental campaign}

The column specimens' overall layout and geometry have been based on suggested sections of representative full-scale composite columns used for high-rise buildings, from Magnusson Klemencic Associates, Seattle (MKA). Overall dimensions of the real-scale columns are $1800 \times 1800 \mathrm{~mm}$, with a height of $9 \mathrm{~m}$ at the lobby level (base of the tower) and $4.5 \mathrm{~m}$ at the typical floor. The experimental campaign is using $1 / 4$ scaled columns due to the lab capacities.

The experimental campaign contains 6 specimens with same geometrical configuration detailed in Fig. 1. The specimens are tested to failure by applying concentrated load, using a 200-tons servo system at Tsinghua University [3]. The experimental setup consists in two hinges, as shown in Fig. 2. One hinge is placed on the ground and fixed by blocks to avoid any horizontal displacements. The other one is placed on the top of the test specimen, connected to a transition beam that serves as a connector between the hinge, horizontal actuator and the vertical actuator.

Sand layers are placed between the test specimens and the hinges, while polytetrafluorethylene plates (PTFE) are placed under the end plates of the steel sections, to make sure that the steel - concrete interface slip can be developed near the test specimen ends to simulate real boundary conditions. In real structures, relative slip may occur along the composite column at any point. If the sand layers and PTFE plates are not provided, the rigid surface of the hinge will force the test specimen end to stay in the same plane. Consequently, the relative displacement between the concrete and the steel sections near the test specimen ends will be restricted, which overestimates the composite column.

Table 1. Obtained material strength (units: $\mathrm{MPa}$ ).

\begin{tabular}{lllllc}
\hline Specimen & $\mathbf{f}_{\text {ck }}$ & $\begin{array}{l}\mathbf{f}_{\mathbf{y}} \\
\text { flange }\end{array}$ & $\begin{array}{l}\mathbf{f}_{\mathbf{y}} \\
\text { web }\end{array}$ & $\begin{array}{l}\mathbf{f}_{\mathbf{y}} \\
\text { rebar }\end{array}$ & $\begin{array}{l}\text { ecc. } \\
{[\%]}\end{array}$ \\
\hline E00-1 & 61.2 & 408 & 523 & & 0.0 \\
E00-2 & 56.6 & 398 & 411 & & 0.0 \\
E10-1 & 59.8 & 423 & 435 & 438 & 12.4 \\
E10-2 & 68.4 & 383 & 415 & & 12.9 \\
E15-1 & 67.5 & 377 & 404 & & 19.9 \\
E15-2 & 75.2 & 389 & 405 & & 17.9 \\
\hline
\end{tabular}

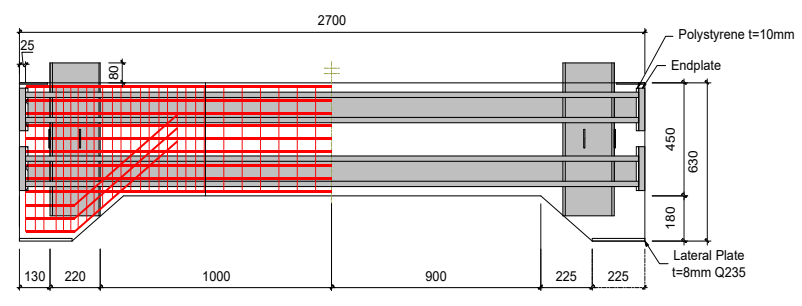

10

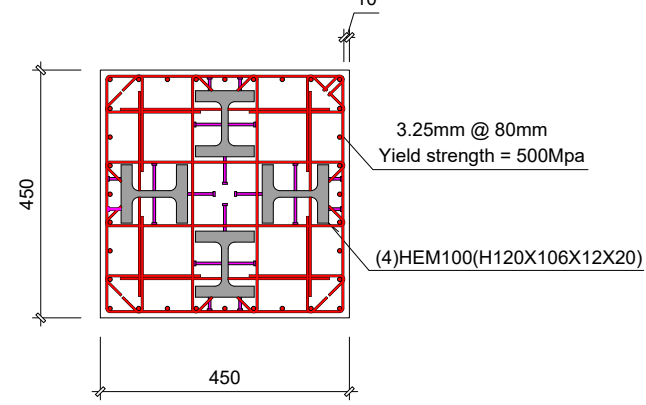

Fig. 1. Static tests details.

The applied loading rate is slow enough to avoid dynamic effects. The imposed load increased to peak value until the specimens failed. Each two of specimens were loaded under same eccentricity ratio e $/ \mathrm{h}: 0 \%, 10 \%$ and $15 \%$. Due to second order effects, the actual eccentricity ratios got larger. The exact values of these eccentricities are presented in Table 1. During the test, the lateral displacement of the transition beam is strictly controlled by the 
horizontal actuators to ensure that the lateral displacement of the top end has zero value.

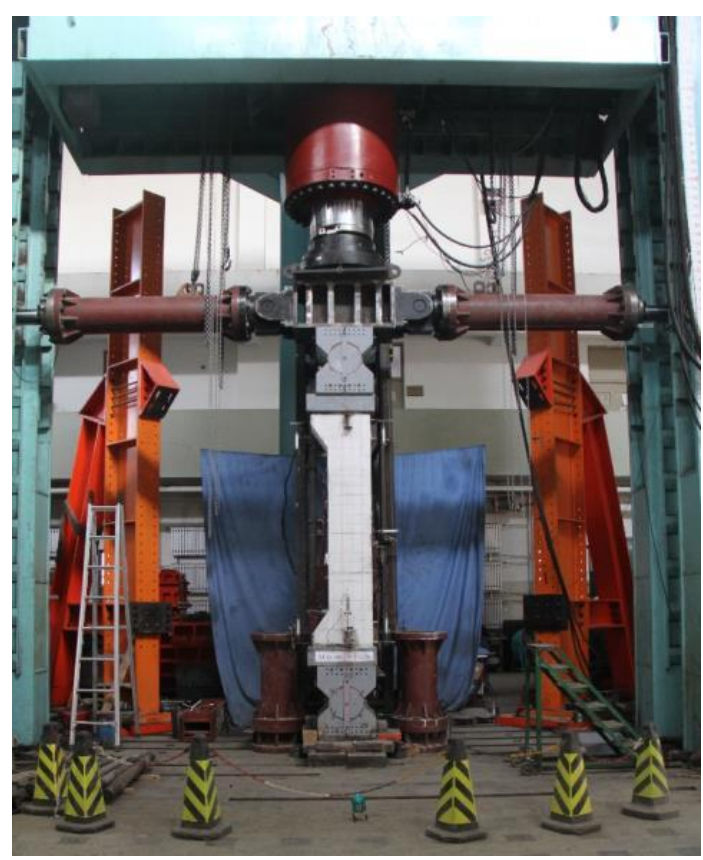

Fig. 2. Test setup.

Specimen E00-1 and E00-2 were loaded with $\mathrm{e} / \mathrm{h}=0$. Since the behavior of these two specimens were very similar, specimen E00-1 is used as an example for description. A vertical crack was observed on the face of the specimen when the axial load reduced about $50 \%$ of the maximum load. The length of the crack grew as the load increased, but no extra cracks occurred. When the axial load reached $70 \%$ of the maximum load, the initial crack stopped growing and ended up in a longitudinal crack in the middle of the column, see Fig. 3 and Fig. 4. The concrete cover at the middle of the column was very thin due to the existence of the steel sections. Therefore, this part of the concrete was weaker than the others, which led to the longitudinal cracking under axial load. In addition, the splitting effect caused by the shear studs might also contribute to the cracking of the concrete. No significant deformations were observed before the maximum axial load was reached.

The eccentric specimens failed in combined compression and bending pattern. No significant deformations were observed before the maximum axial load was reached. The horizontal deflection of the column developed rapidly after the maximum load was reached, so the actual eccentricity ratio on the mid-height cross section was enlarged due to the second order effect, and horizontal cracks occurred on the tension side of the column. Meanwhile, damage of the concrete on the compression side of the column kept developing. In the end, the test was stopped when the concrete on the compression side was severely damaged.
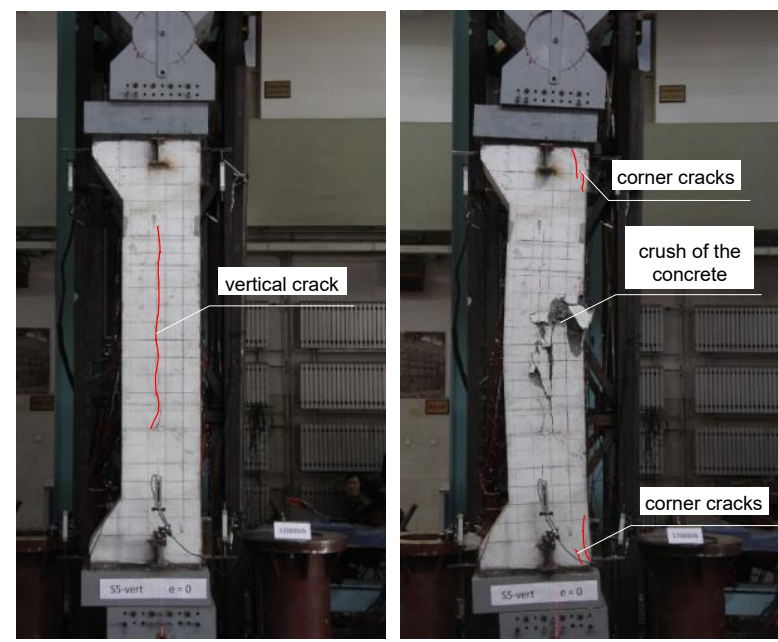

Fig. 3. Crack development of specimens subjected to axial load.
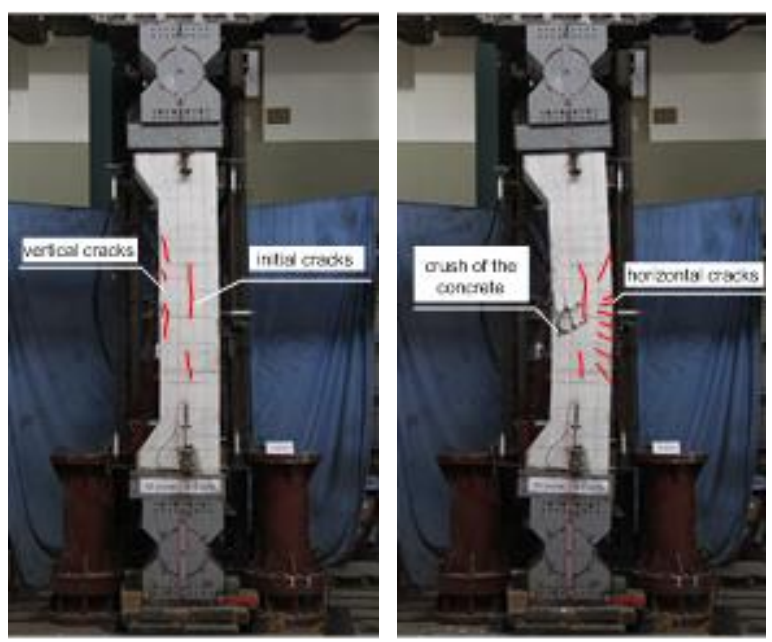

Fig. 4. Crack development of specimens subjected to eccentric loads.

The axial load - vertical deflection curves are presented in Fig. 11. The axial load of specimens E00-1 an E00-2 showed two sudden drops during the test. The first drop occurred right after the maximum load was reached, and the axial load dropped to $70 \%$ of the maximum value. Then, the axial load gradually decreased from $70 \%$ to $60 \%$ of the maximum load, while the vertical deflection was developing rapidly. When the axial load had decreased to about $60 \%$ of the maximum load, the second drop in axial load occurred, accompanied by the sudden crush of the concrete in the middle of the column. In comparison, no sudden drops in 
axial load were detected for the eccentrically loaded specimens. After the maximum loads were reached, the axial loads of these four specimens gradually decreased until failure.

Table 2 lists the capacities and the corresponding bending moments on the midheight cross section of the columns. The bending moment was determined by Eq. (1):

$$
M=N\left(e_{i}+\delta\right)
$$

where $e_{i}$ is the initial eccentricity of the specimen, and $\delta$ is the horizontal deflection of the mid-height cross section due to the second order effect. Although the initial eccentricity of specimen E00-1 and E00-2 was zero, horizontal deflections of these two columns were recorded during the test. Nevertheless, the eccentricities were very small under the maximum load level, so that the axial resistances of these two specimens were not significantly influenced.

For specimens subjected to eccentric loads, the eccentricities under the maximum load level were $19 \% \sim 33 \%$ larger than the initial eccentricities due to the second order effect. Since this paper deals with short columns, the second order effect will not be discussed in detail.

Table 2. Specimens capacities (units: $\mathrm{kN}, \mathrm{m}$ ).

\begin{tabular}{cllcl}
\hline Spec. & $\mathbf{N}_{\max }$ & $\mathbf{M}_{\max }$ & $\begin{array}{c}\text { Rcc } \\
\text { Ratio }\end{array}$ & efailure/einitial \\
\hline E00-1 & 17082 & 143 & $1.9 \%$ & --- \\
E00-2 & 15325 & 52 & $0.8 \%$ & --- \\
E10-1 & 14360 & 803 & $12.4 \%$ & 1.24 \\
E10-2 & 13231 & 767 & $12.9 \%$ & 1.29 \\
E15-1 & 12041 & 1076 & $19.9 \%$ & 1.33 \\
E15-2 & 12759 & 1026 & $17.9 \%$ & 1.19 \\
\hline
\end{tabular}

Fig. 5 and 6 represent the curvature development for specimens E10-1 and E15-1. Similar behavior was observed for specimens E10-2 and E15-2. A linear regression is created using points of normal stain versus relative position under a certain load level. Then, the slope of the regressed straight line is taken as the curvature. The obtained curvature of the concrete correlates with that of the steel section very well. Together with the validation of 'Plane Section Assumption', it is reliable to assume the curvatures of different materials on a particular section are the same. The column curvature was calculated by normal strain of the steel sections. In addition, it can be observed that the curvature developed more rapidly when the load level was beyond $60 \%$, indicating the reduction of bending stiffness.

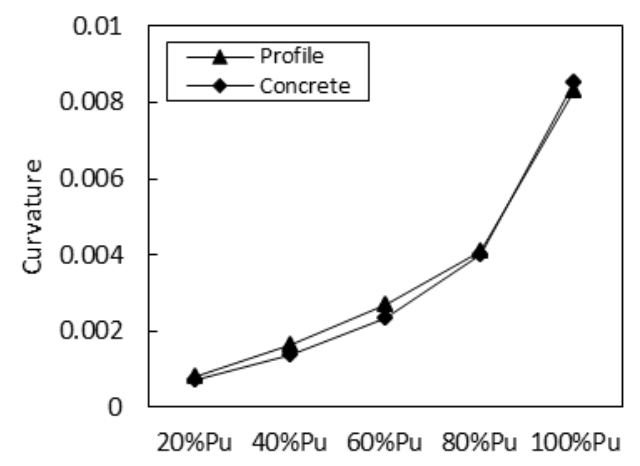

Fig. 5. Curvature development at mid-height for specimens E10-1 and E10-2.

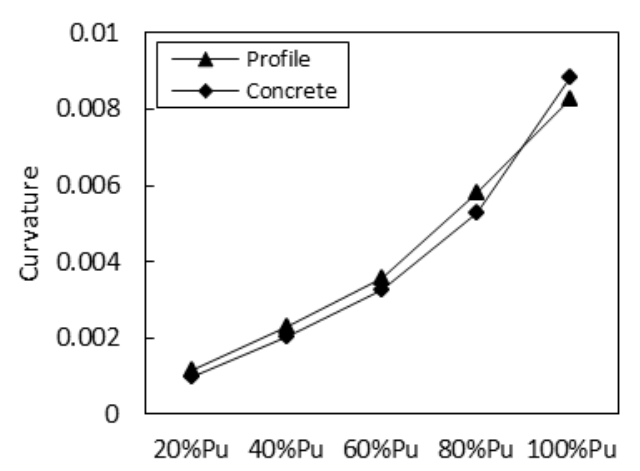

Fig. 6. Curvature development at mid-height for specimen E15-1.

The experimental value of the effective flexural stiffness can be determined using the curvature definition of the beam theory. The Euler- Bernoulli beam theory defines the curvature using the Eq. (2):

$\chi=\frac{1}{\rho}=\frac{M}{(E I)}$

Where: $\chi$ is the curvature and $\rho$ the radius of curvature.

The reduction factor for flexural rigidity can be defined using the following approach:

$$
M=\left(E_{y} \cdot I_{y}+E_{s} \cdot I_{s}+R_{b}^{k} \cdot E_{c m} \cdot I_{c}\right) \cdot \chi
$$

Where $E_{\mathrm{y}}, \mathrm{E}_{\mathrm{s}}$ and $\mathrm{E}_{\mathrm{cm}}$ are the Young's modulus of the steel profile, rebar and respectively the concrete part; $I_{y}, I_{s}$ and $I_{c}$ are the moment of inertia of the steel profile, rebar and respectively the concrete part. 
The reduction factors $\mathrm{R}_{\mathrm{b}}{ }^{\mathrm{k}}$ is determined according to Eq. (4):

$$
R_{b}{ }^{k}=\frac{(E I)_{\text {eff_experimentaly }}-E_{y} \cdot I_{y}-E_{s} \cdot I_{s}}{E_{c m} \cdot I_{c}}
$$

The comparison between the theoretical and experimental values is presented in Table 3. It can be observed a good accuracy of the current design codes, having a difference in value is under $10 \%$.

Table 3. Stiffness reduction factors - comparison.

\begin{tabular}{cccc}
\hline \multirow{2}{*}{ Spec. } & \multicolumn{3}{c}{$\mathbf{R}_{\mathbf{b}}{ }^{\mathbf{k}}{ }_{\text {_EN1994 }}$} \\
\cline { 2 - 4 } & EC4 value & Experimental & Ratio \\
\hline E10_1 & 0.6 & 0.462 & $130 \%$ \\
E10_2 & 0.6 & 0.599 & $100 \%$ \\
E15_1 & 0.6 & 0.612 & $98 \%$ \\
E15_2 & 0.6 & 0.599 & $100 \%$ \\
E10_1 & 0.6 & 0.462 & $130 \%$ \\
\hline
\end{tabular}

The calculated values for the modulus of elasticity according to EN 1994 design code are given in Table 4. It can be observed that the comparison values are under $10 \%$ in difference. In conclusion, the methods for the evaluation of effective flexural stiffness developed in the EN 1994 can be considered for composite sections reinforced with several steel profiles having an eccentricity loading ratio less than $15 \%$.

Table 4.Specimens E10-1 E15-2 - Effective flexural stiffness - comparison.

\begin{tabular}{cllc}
\hline \multirow{2}{*}{ Spec. } & \multicolumn{2}{c}{ EI $_{\text {eff }} \mathbf{N m m}^{2}$} & Ratios \\
\cline { 2 - 4 } & EN 1994-1 & Exp & EC4/Exp \\
\hline E10_1 & $1.23 \mathrm{E}+14$ & $1.26 \mathrm{E}+14$ & $98 \%$ \\
E10_2 & $1.27 \mathrm{E}+14$ & $1.23 \mathrm{E}+14$ & $97 \%$ \\
E15_1 & $1.25 \mathrm{E}+14$ & $1.33 \mathrm{E}+14$ & $94 \%$ \\
E15_2 & $1.26 \mathrm{E}+14$ & $1.21 \mathrm{E}+14$ & $96 \%$ \\
\hline
\end{tabular}

\section{Validation of FEM and adapted code methods with the test results}

\subsection{Adapted Plastic Distribution Method}

EN 1994-1 - Clause 6.7 provides two design methods in the design of composite compression members with encased sections, partially encased sections and concrete filled rectangular and circular tubes.

The first method is a numerical and general method, while the second one is a simplified analytical method, applied only to doubly symmetrical sections and uniform along the height of the element. By using the simplified method, the interaction curve can be approached by a succession of lines joining 4 characteristic points $\mathrm{A}, \mathrm{B}, \mathrm{C}, \mathrm{D}$, as shown in figure below.

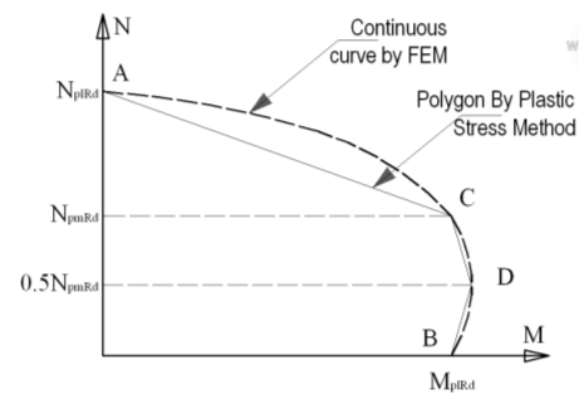

Fig. 7. EN 1994 - 1: Simplified method.

The following assumptions should also be considered, because are underlying the prescriptions from EN 1994 - 1: There is a complete interaction between steel and concrete, the plane sections remain plane after deformation an the concrete resistance in traction is neglected.

In the adapted method, the required calculation of geometrical characteristics of the section (moment of inertia) is based on a simplified representation of the reinforcement steel and steel section geometry, as equivalent plates and rectangles respectively as shown in Fig. 8.

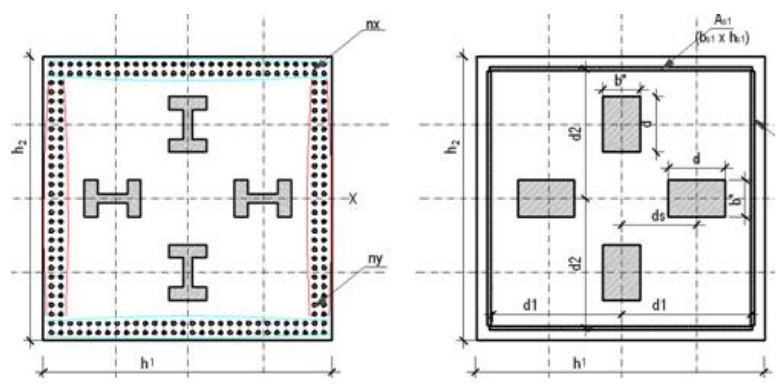

Fig. 8. EN 1994 - 1: Simplified method.

The presented method in accordance to EN 1994-1 allows to evaluate the nominal resistance of the composite column calculations, based on the plastic stress distribution of the composite cross sections. A two-step calculation can be used to determine the flexural resistance of the composite cross section, as shown in Table 5 [6]:

Step 1: Determine the position of the neutral axis (N.A.) based on the balance condition of 
the axial load. There are four distinct situations of the position of the N.A are identified.

Step 2: Calculate the flexural resistance of the composite cross section based on the position of the N.A. CL represents the neutral axis of the cross section.

Table 5.Stress block distribution for rectangular column with 4 encased profiles [5].

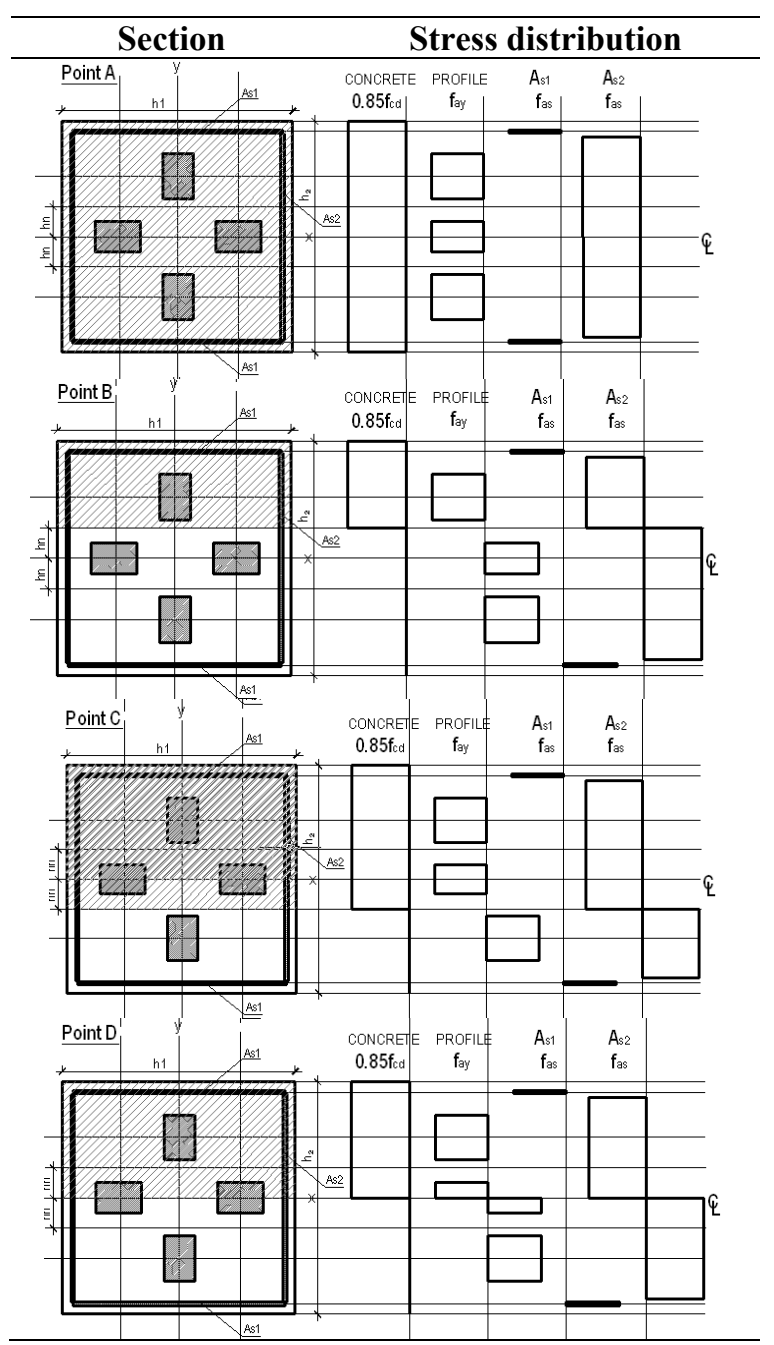

\subsection{FEM simulations and results comparison}

Software Abaqus has been chosen for the FEM analyses subjected to axial load.

The definition of the concrete behavior has been made by using a concrete damage plasticity model. The uniaxial constitutive law for concrete material has been obtained using the EN 1992 material law as show in Fig. 9

A bilinear constitutive model is adopted for longitudinal bar and for the steel profiles, where fu and $f_{y}$ are obtained from the experimental tests.
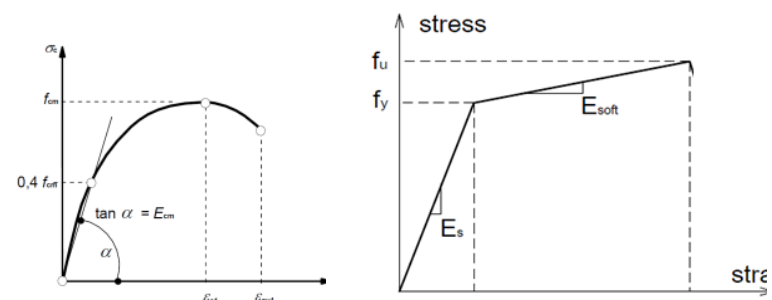

Fig. 9. Material constitutive curves.

The numerical model created in Abaqus, is presented in Fig. 10 and contains a simplification of the experimental part. The column is considered with a constant cross section of $450 \times 450 \mathrm{~mm}$. The concrete and the steel sections are simulated by three dimensional eight-mode solid elements and the rebars are simulated by two dimensional threenode truss element. The interface between concrete and steel profiles is TIE connected, while the rebars are perfectly embedded in the concrete part.
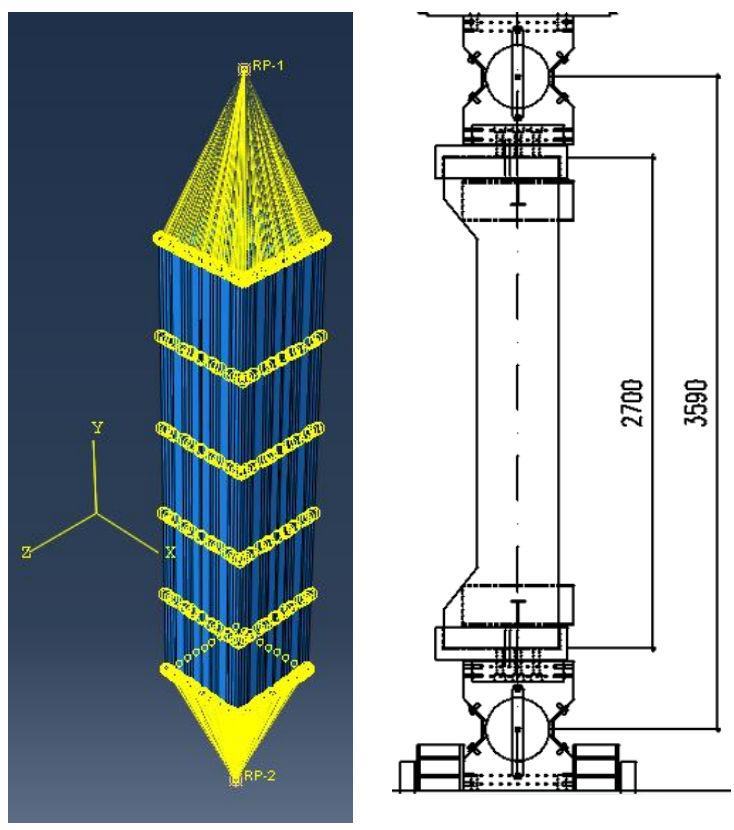

Fig. 10. FEM numerical model.

To keep the buckling length chosen by the experimental part of $3.59 \mathrm{~m}$, the boundary conditions are defined through the reference points that are offset from the specimens.

Before peak point, the simulated axial load vs. vertical displacement' curve follows similar paths to the experimental curve as shown in Fig. 11. The reduction of the axial capacity occurred due to the degradation of material strength, cracks in the concrete, spill and damage of the concrete and buckling of the longitudinal bars. Small divergencies between 
the FEM and the experimental test could be noticed especially for $0 \%$ eccentricity specimens, due to the implemented numerical model of concrete.
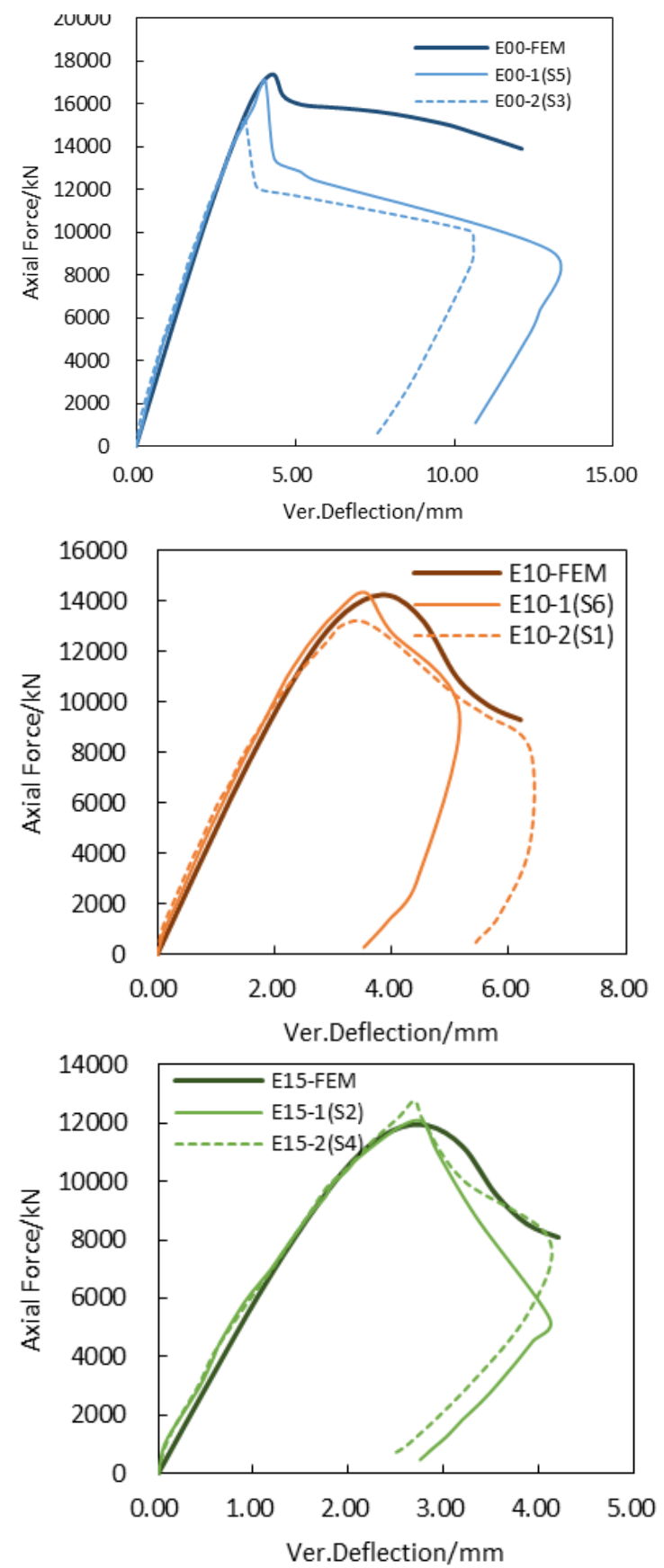

Fig. 11. Axial force vs. vertical deflection [5].

The FEM and analytical interaction curves, presented in Fig. 12, show results like the capacity of the experimentally tested mega column. The Fiber model represents the classical pivot method developed for the reinforced concrete structural elements, where the strains are considered linear along the crosssection [7], [9].

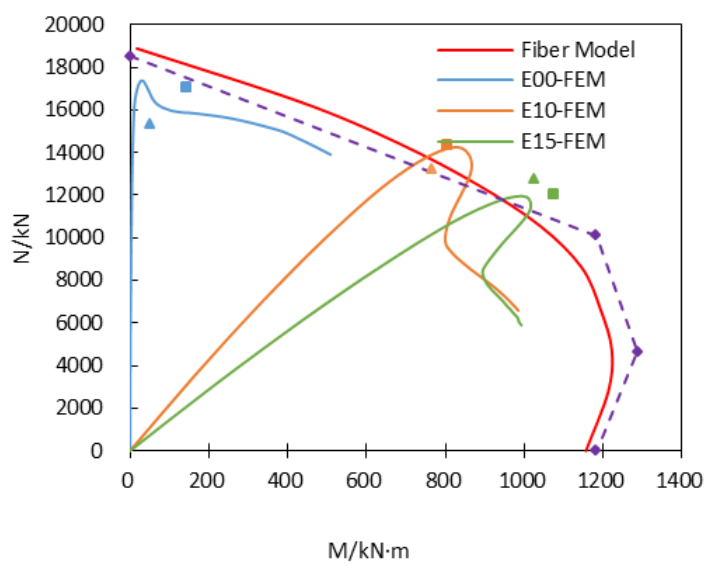

Fig. 12. N -M interaction curve: comparison between FEM and experimental model

Table 6 presents the numerical values of the axial load vs. vertical displacement curves. The numerical results are under $10 \%$ difference from the experimental tests. In conclusion the simplifications made for the numerical model can be used for a further sensitivity study.

Table 6. Axial force capacity - comparisons (units: $\mathrm{kN}, \mathrm{mm}$ ).

\begin{tabular}{cllll}
\hline \multirow{2}{*}{ Specimen } & \multicolumn{2}{c}{$\begin{array}{c}\text { Experimental } \\
\text { values }\end{array}$} & \multicolumn{2}{l}{$\begin{array}{l}\text { Numerical } \\
\text { values }\end{array}$} \\
\cline { 2 - 5 } & $\mathrm{P}_{\exp }$ & $\Delta_{\exp }$ & $\mathrm{P}_{\text {num }}$ & $\Delta_{\text {num }}$ \\
\hline $00-1$ & 17082 & 4.17 & 17006.8 & 3.98 \\
E00-2 & 15325 & 3.43 & 15879 & 4.25 \\
$\mathrm{E} 10-1$ & 14360 & 3.55 & 14500 & 3.60 \\
$\mathrm{E} 10-2$ & 13231 & 3.46 & 14031 & 3.34 \\
$\mathrm{E} 15-1$ & 12041 & 2.79 & 12521 & 3.35 \\
$\mathrm{E} 15-2$ & 12759 & 2.70 & 13012 & 3.43 \\
\hline
\end{tabular}

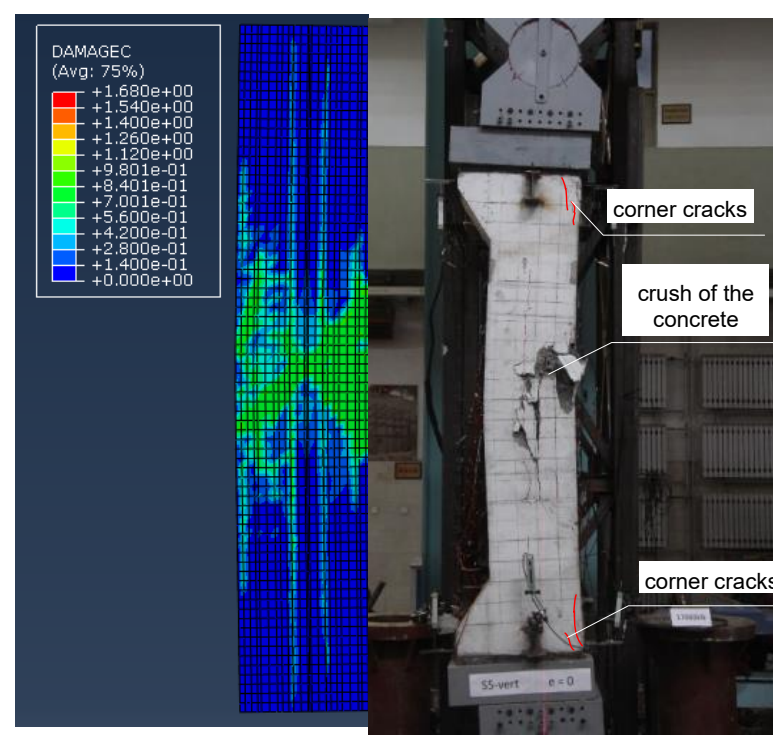

Fig. 13. Crack comparison for specimens subjected to axial loads. 
The crack comparison between the numerical and experimental model is presented in Fig. 13 for specimens subjected to concentric loads. The numerical model simulated similar deformation behavior as the experimental test. The cracks and concrete crushing are formed in an equivalent manner in both cases.

\section{Conclusions}

Six $1 / 4$ scaled concrete encased composite columns with multi-separate steel sections were tested to understand better their performance and ductility behavior. The test results were in accordance with the expected results and the specimens shown sufficient deformation capacity. The specimens are able to maintain the bending moment at the maximum requirement, while the curvature is developed until column failure.

The full composite action was observed during the tests, even though the steel sections are not connected to one another. Test results of this test program reveal that the 'Plane Section Assumption' is generally valid for specimens with an $\mathrm{e} / \mathrm{h}=10 \%$ and an $\mathrm{e} / \mathrm{h}=15 \%$, but the interface slip grew with the eccentricity, which suggests that the shear demand is relatively larger for mega columns.

The concrete core, surrounded by the steel profiles, is highly confined, thus increasing the ductility of the composite column

Available design standards are providing no information on how to properly design reinforced column sections with more than one embedded steel profile. For this, a new extended method based on Eurocode 4 simplified design method has been developed in order to propose a design guidance for composite columns with several steel profiles embedded. The method is an extension of the Plastic Distribution Method and takes into account all the simplified assumptions that are defined in EN 1994-1 - Clause 6.7.

The results of the experimental campaign have been validated with FEM methods and compared with simplified code provisions methods. The comparison shows matching results.
The simplifications brought to the numerical simulations can be adapted for further parametric studies.

The simple adapted method can be used to perform "hand-made" evaluation of the axial force-bending moment interaction curve.

\section{Summary and acknowledgments}

This project was coordinated by the Council of Tall Buildings and Urban Habitat (CTBUH). The structural engineering firm Magnusson Klemencic Associates (MKA) provided background studies on composite mega columns projects. The China Academy of Building Research (CABR) was engaged to develop the testing program for the subject columns. The authors gratefully acknowledge the support and contributions from these organizations.

\section{References}

[1] Ye L, Ehua F. State-of-the-art of study on the behaviors of steel reinforced concrete structure. China Civil Engineering Journal 2000; 33(5): 111.

[2] EN 1994-1-1. Eurocode 4: Design of composite steel and concrete structures - Part 1-1: General rules and rules for building; 2004.

[3] Deng $F$ et al. Performance and capacity of isolated reinforced concrete columns and design approaches. CABR testing report, Beijing, China; 2015.

[4] Xiao C, Deng F. Experimental study on concrete encased composite columns with separate steel sections. Steel and Composite Structures 2017; 23(4): 483-491.

[5] Gerardy JC et al. Composite mega columns: testing multiple, concrete-encased, hot rolled steel sections. CTBUH publication; 2016.

[6] Plumier et al. Design of columns with several encased steel profiles for combined compression and bending. Final report created for ArcelorMittal website; 2012

[7] Ye L, Ehua F. State-of-the-art of study on the behaviors of steel reinforced concrete structure. China Civil Engineering Journal 2000; 33(5): 111.

[8] ANSI/AISC 260-16. Specification for Structural Steel Buildings; 2016.

[9] EN 1992-1-1. Eurocode 2: Design of concrete structures - Part 1-1: General rules and rules for buildings; 2004. 